\title{
The Application of WorkFlow Management System Based on Rules and Roles
}

\author{
Qiang Wang \\ School Of Software \\ University of Science and Technology Liao Ning \\ Anshan Liaoning 114000 China \\ lancet_wang@126.com
}

\begin{abstract}
Workflow technology continues to be subjected to on-going development in its traditional application areas of business process modeling and business process coordination[1] .It can improve the efficiency and manageability of an enterprise's daily teamwork .Traditionally, it is not easy for the workflow modeling method to describe the complex business process clearly and intuitively[2] .In this paper, we improve the role based workflow model and introduces definition and enactment models to characterize workflows. In the way ,flexible modeling and enactment of business process is supported allowing changes even during execution.Finally,an example of Financial Reimbursement System is demonstrated to prove the convenience and feasibility about the method mentioned.
\end{abstract}

Keywords- workflow; rolse;rules; financial

\section{INTRODUCTION}

Workflow Management Systems (WFMS) have been introduced to support the design execution and monitoring of generally long-lasting business processes. A business process also called workflow, typically consists of various activities which have to be executed in some order involving multiple collaborating persons called transactor in a distributed environment to fulfill a certain task in an organization [3] . In recent years, some researchers proposed that the workflow is driven by goal, the transactor played typecast role is the decisive factor[4]. Compared with the traditional workflow model, it is the describing based on role can describe the dynamic of the process better and adapt frequently changing requirements. In the following we introduce an improving workflow model based on role, making some rules such as multi-role, execution order of role decided by the weight and so on .And an example of Financial Reimbursement Management System is demonstrated to improve the feasibility.

\section{Business PROCESSES}

The perspectives of finance reimbursement pay attention to how people involved in the process cooperate. The functional aspect declares what has to be done, the behavioral aspect says when it has to be done, the organizational aspect denotes who has to do it, and the informational aspect describes which information is exchanged between cooperating transactor. In order to give an idea of how the aspects introduced above act in combination, we discuss the example of tobacco enterprise. There is thirteen departments owning enterprise with one president and two vice-presidents .Financial reimbursement subject in the enterprise involves nine kinds of expenses in total , including entertainment expense, training expense ,travel expense and so on. There are differences in reimbursement business processes both among different reimbursement subjects and the same reimbursement subjects but different department. Some of the expense must be examine by the function department and they need different function department to examine among different reimbursement subjects also. It has a total number over one hundred of reimbursement processes in the enterprise. Here we take the travel expense reimbursement flow of the human resource department, marketing department and financial management department for example. (cf. Figure 1.2.3).)

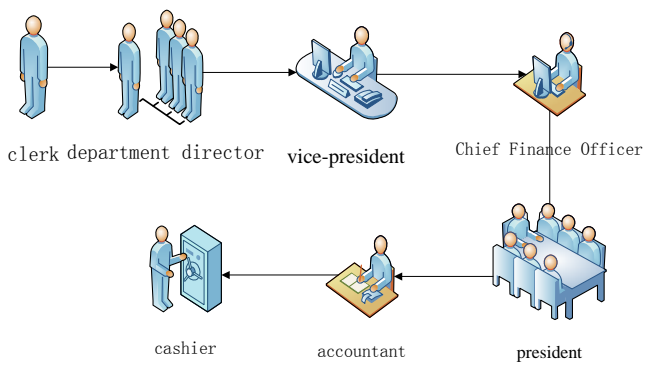

Figure 1. Travel expense reimbursement flow of human resource department

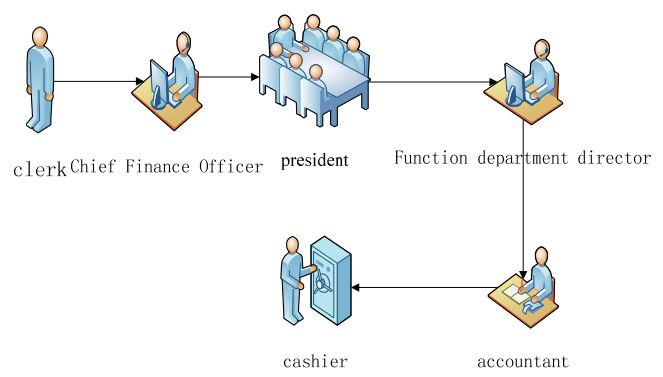

Figure 2. Travel expense reimbursement flow of financial management department 


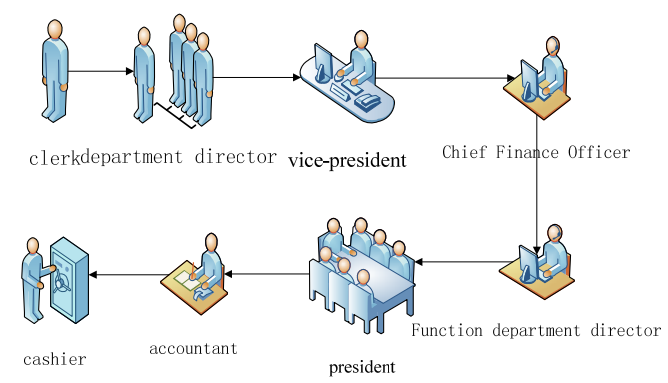

Figure 3. Travel expense reimbursement flow of marketing department

According to general workflow modeling method base on role .we can express the over hundreds reimbursement process with 20 workflow models. However it is still go against the design and development of workflow management system .we can see that the traditional modeling method can't show the complex and practical business process clearly and intuitively by building only one workflow model.

\section{SOLUTION}

In order to describe the complex enterprise business processes clearly and intuitively. We improved the rolecentric work modeling and prescribed:

\section{A. THE ROLE MODEL}

To cope with changing personnel, WFMS require the separation between role and transactor performing them. Transactor can learn and forget roles dynamically, they can play several roles at the same time, and they even can play the same role simultaneously several times, as is required by real-world transactor.

\section{B. THE RULE MODEL}

This need for flexible from the fact that workflow applications are subject to frequent changes caused by the business environment Flexibility and adaptability is required:

- The weight of role: Assign different roles for the process weight, With figures that the smaller number, the higher priority;

- Role Selection: In the process transactor in order of weight form high to low to implement the processing operation, We select the lowest weight role to login when the transactor play several roles at the same time, especially Initiating a process or returning the expenses documents back;

- Transactor Selection: For each activity one or more transactor have to be selected by means of transactor selection policies. The decision which transactor to select for a specific activity is based on information concerning both the subject of expense and the documents processed by the actual workflow;

- Automatic Skip: if treatment were already done by transactor using a high-weight role of the operation of a flow who also played other lower weight roles in the process, then when the execution of the process to the corresponding nodes of these roles , The process automatically skip;

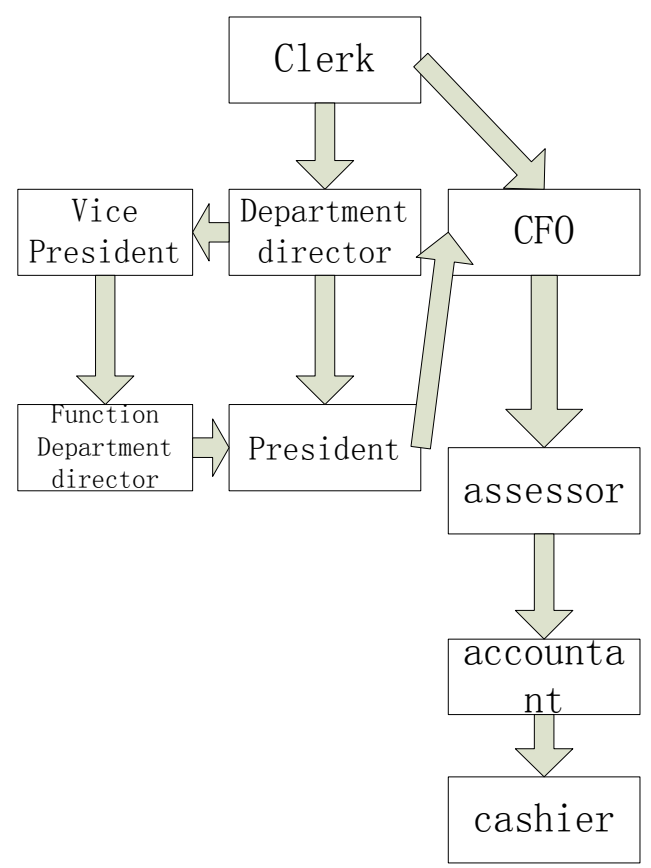

Figure 4. Workflow Design of system

As reimbursement workflow model is shown in Figure 4, we add another role function department director to the transactor who plays one role as department director before, another role of manager to the transactor who plays one role as presidents before ,etc. The rest can be down in the same manner the role of department director for financial, the role of manager for chief financial officer. These transactors who play multi-role in the processing of execute order decided by the rules we mentioned over. According to the above four rules to establish the role based workflow model, in the face of the complex business process modeling, we can greatly reduce modeling difficulty and simplify modeling.

\section{WORKFLOW DESIGN OF ENTERPRISR FINANCIAL REIMBURSEMENT MANAGEMENT SYSTEM}

In the case of this paper, we have designed and implemented an Enterprise Financial Reimbursement Management System on the basis of the solution mentioned in last section which is made full user of in managing the complex financial reimbursement business processes. According to the solution, we can building workflow model clearly and intuitively for the Enterprise as show in Figure 4. Every Role can return the application to any node executed except the roles of treasurer and accountant in the model. 


\section{DESIGN OF ENTERPRISE FINANCIAL REIMBURSEMENT MANAGEMENT SYSTEM}

\section{A the Architecture of Enterprise financial Reimbursement Management}

As shown in Figure 5, the system is based on B/S structure and adopts popular Struts2.0+Spring2.5+Hibernate3.1 framework, which is sufficiently restricted in hierarchical structure of MVC. With the user of this design pattern, we not only isolate function module and display module, but also efficiently improve the maintainability, extensibility, portability and reusability of this system. The persistence layer development using the open source Hibernate framework, which is an independent object persistence layer (Object Persistence Layer) .May, be to avoid JDBC underlying database using Hibernate, Frequent access, so that we focus more on the development of the business logic. The System is implemented by Struts framework; And using dependency injection of Spring framework to integrate data persistence layer, interface layer, DAO layer, business logic layer. service layer with presentation layer, so that low coupling between various layers can be achieved.

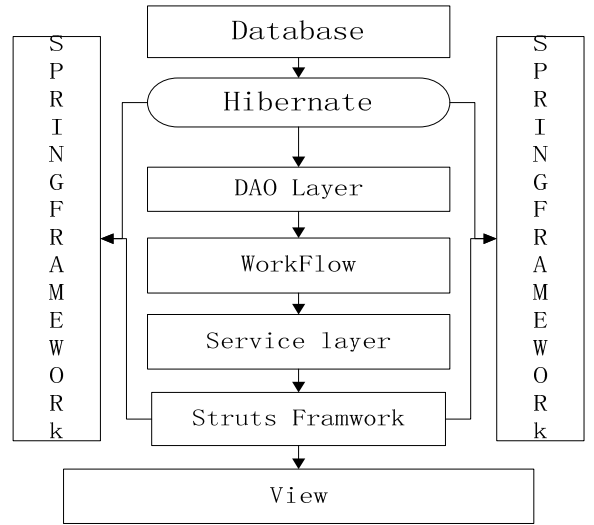

Figure 5. Architecture of system

\section{B. Specific Design of the system}

The part of background management of system is for use of administrators ,use mostly in maintaining system data, such as workflow managing, staff management, flowType management ,node management staff, assignment role to staff and so on . It's class diagram is shown as Figure 6 .On the other hand, the foreground of system offers a variety of application, including personal data modifying, workflow information, setting role's weight, applying for reimbursement, dealing applications, affiche information and so on. It's class diagram is shown as Figure 7

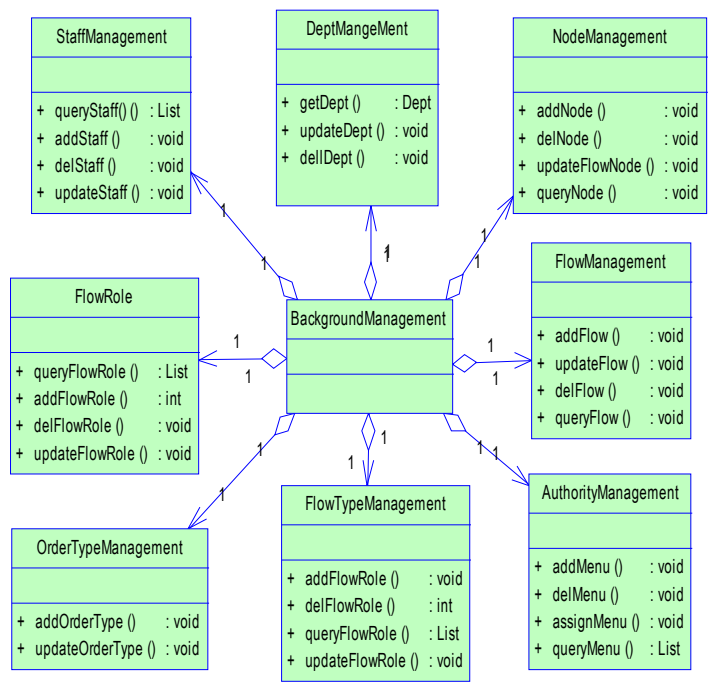

Figure 6. Class diagram of foreground
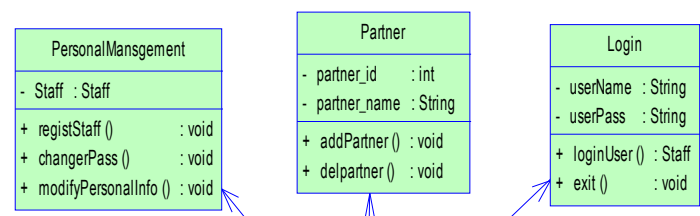

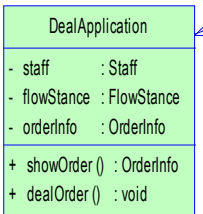
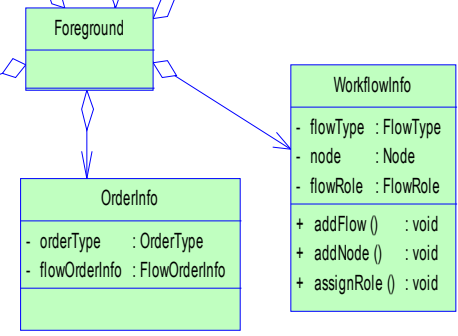

Figure 7. Class diagrame of backfround management

\section{Application Running View}

The system developed according to the plan above is shown as Figure 8.

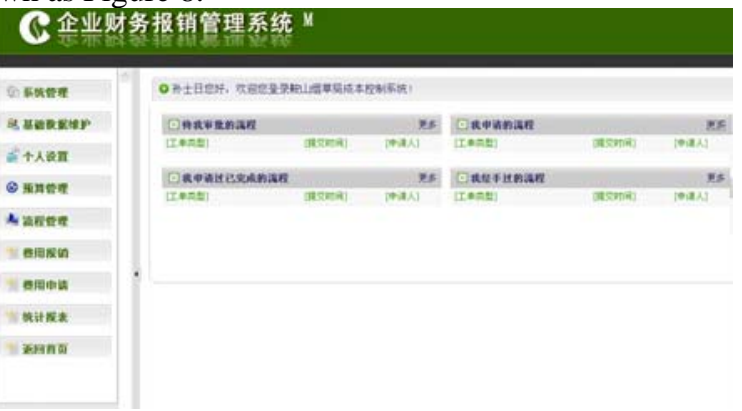

Figure 8. Fig. 8 Enterprise Financial Reimbursement Management System 


\section{CONCLUSION}

Through improving the role based workflow model, the article comes up with a workflow modeling method based on multi-role playing. It is possible to make the modeling easier and simpler when we come to the complex business process modeling problems.

It shows the outstanding advantages of convenience, facility, practicality, expansibility, transaction and Financial Reimbursement System based on B/S structure.

\section{REFERENCES}

[1] W.M.P. VAN DER AALST A.P. BARROSWorkflow Patterns Distributed and ParallelDatabases, 14, 5-51, 2003

[2] Jianxun liu, Shengsheng zhang , and Jinming Hu , A case study for an inter-enterprise workflow-support supply chain management system Information \&Management,Vol.42 ,March 2005,pp 441-454

[3] Jablonski, S., and Bussler, C. 1996. Workflow-Management: Modeling Concepts, Architecture and Implementation. International Thomson Computer Press, 1996.
[4] Hung, P. C. K. (2001), Secure Workflow Model, Ph.d., Department of Computer Science, TheHong Kong University of Science and Technol-ogy, Hong Kong.

[5] Kappel, G., Lang, P., Rausch-Schott, S., and Retschitzegger, W., 1995.

Workflow Management based on Objects, Rules and Roles. IEEE Data Engineering Bulletin, Special Issue on Workflow

[6] Kang, M. H., Park, J. S. \& Froscher, J. N. (2001), Access ControlMechanisms for Inter-organizational Workflow, in Proceedings of the Sixth ACM Symposium on Access Control Models and Tech-nologies', pp. 66-74.

[7] Keen, Peter, Shaping the Future: Business Design through Information Technology, Boston: Harvard Business School Press, 1991.

[8] Gottlob, G., Schrefl, M., and Röck, B. 1996. Extending ObjectOriented Systems with Roles.ACM Transactions on Information Systems, 14(3), 268-296.

[9] Bussler, C. and S. Jablonski. 1994a. "An Approach to Integrate Workflow Modeling and OrganizationModeling in an Enterprise.” Proc. Third IEEE Workshop on Enabling Technologies: Infrastructure for Collaborative Enterprises (WET ICE), Morgantown, WV 